\title{
Future Mobile Device Usage, Requirements, and Expectations of Physicians in German University Hospitals: Web-Based Survey
}

Oliver Maassen ${ }^{1,2}$, MSc; Sebastian Fritsch ${ }^{1,2}$, MD, Dr; Julia Gantner ${ }^{2,3}$, MSc; Saskia Deffge ${ }^{1,2}$, MSc; Julian Kunze ${ }^{1,2}$, MD, Dr; Gernot Marx ${ }^{1,2}$, MD, Prof Dr, FRCA; Johannes Bickenbach ${ }^{1,2}$, MD, Prof Dr

${ }_{1}$ Department of Intensive Care Medicine, University Hospital RWTH Aachen, Aachen, Germany
${ }^{2}$ SMITH Consortium of the German Medical Informatics Initiative, Leipzig, Germany
${ }^{3}$ Institute of Medical Statistics, Informatics and Data Science, Jena University Hospital, Jena, Germany

Corresponding Author:

Oliver Maassen, MSc

Department of Intensive Care Medicine

University Hospital RWTH Aachen

Pauwelsstrasse 30

Aachen, 52074

Germany

Phone: 492418080444

Email: oliver.maassen@rwth-aachen.de

\section{Abstract}

Background: The use of mobile devices in hospital care constantly increases. However, smartphones and tablets have not yet widely become official working equipment in medical care. Meanwhile, the parallel use of private and official devices in hospitals is common. Medical staff use smartphones and tablets in a growing number of ways. This mixture of devices and how they can be used is a challenge to persons in charge of defining strategies and rules for the usage of mobile devices in hospital care.

Objective: Therefore, we aimed to examine the status quo of physicians' mobile device usage and concrete requirements and their future expectations of how mobile devices can be used.

Methods: We performed a web-based survey among physicians in 8 German university hospitals from June to October 2019. The online survey was forwarded by hospital management personnel to physicians from all departments involved in patient care at the local sites.

Results: A total of 303 physicians from almost all medical fields and work experience levels completed the web-based survey. The majority regarded a tablet $(211 / 303,69.6 \%)$ and a smartphone $(177 / 303,58.4 \%)$ as the ideal devices for their operational area. In practice, physicians are still predominantly using desktop computers during their worktime (mean percentage of worktime spent on a desktop computer: 56.8\%; smartphone: $12.8 \%$; tablet: $3.6 \%$ ). Today, physicians use mobile devices for basic tasks such as oral $(171 / 303,56.4 \%)$ and written $(118 / 303,38.9 \%)$ communication and to look up dosages, diagnoses, and guidelines $(194 / 303,64.0 \%)$. Respondents are also willing to use mobile devices for more advanced applications such as an early warning system $(224 / 303,73.9 \%)$ and mobile electronic health records $(211 / 303,69.6 \%)$. We found a significant association between the technical affinity and the preference of device in medical care $(\chi \mathrm{s} 2=53.84, P<.001)$ showing that with increasing self-reported technical affinity, the preference for smartphones and tablets increases compared to desktop computers.

Conclusions: Physicians in German university hospitals have a high technical affinity and positive attitude toward the widespread implementation of mobile devices in clinical care. They are willing to use official mobile devices in clinical practice for basic and advanced mobile health uses. Thus, the reason for the low usage is not a lack of willingness of the potential users. Challenges that hinder the wider adoption of mobile devices might be regulatory, financial and organizational issues, and missing interoperability standards of clinical information systems, but also a shortage of areas of application in which workflows are adapted for (small) mobile devices.

(J Med Internet Res 2020;22(12):e23955) doi: 10.2196/23955

\section{KEYWORDS}

mobile devices; mobile applications; apps; mHealth; smartphones; tablets; device usage; requirements; expectations; hospital; working equipment 


\section{Introduction}

The usage of mobile devices, especially smartphones, has substantially increased, up to $95 \%$ in nearly all age groups in Germany [1]. With amazing advancement in mobile computer technology and connectivity, mobile devices have already revolutionized communication [2] as well as social media, mobility, fitness tracking, and further mobile health (mHealth) technologies, thus offering the potential to innovate health care inside and outside of clinical settings. The improvement of self-management as well as the effectiveness of the use of mHealth in professional medicine has been proven for several medical conditions, for example, the management of different chronic diseases such as arterial hypertension, diabetes or coronary heart disease, but also the management of acute diseases such as cardiac arrest and stroke [2-5]. Some authors even see smartphones as portable, multifunctional tools with the potential to become "the new stethoscope for physicians [6]." Increasingly, patients and the general population are being encouraged to take responsibility for their own health by actively monitoring their physiological parameters with smartphones, apps, and fitness trackers [7-10].

A fundamental component of the operationalization of mHealth is the usage of mobile devices, especially smartphones and tablets, by patients or health care professionals. The central areas of utilization of mobile devices in hospitals are (1) oral and written communication [11-15]; (2) documentation, organization, and information [16-19]; (3) decision support, notifications, and alarms [20-23], (4) education and professional training [24-28]; and (5) self-monitoring by physicians [29]. Taken together, physicians use mobile devices to assure their own decisions in a clinical environment and to increase efficiency in their workplaces [30].

The benefits of the usage of mobile devices in health care is counterbalanced by problems such as the colonization of surfaces with harmful pathogens or the distraction of medical staff [31,32]. Even more relevant are regulatory and organizational barriers for the implementation of mHealth apps on mobile devices in hospitals, missing standards for the development of health apps, information safety issues, and privacy concerns $[12,33,34]$. Furthermore, the parallel use of private devices for professional and private purposes is common [6], and thus further impacts data protection and patients' privacy.

Both the combination use of mobile devices privately and on duty, and the physician's attitude toward its deployment for so many different areas of utilization, make a structured systematic overview of actual needs difficult. There are hardly any data on the use of mobile devices in hospitals for clinical applications. Therefore, we aim to evaluate the current usage of mobile devices of physicians in German university medical centers and to explore their opinion and perceived needs regarding mobile devices.

\section{Methods}

\section{Study Design, Data Collection, and Recruitment}

For the preparation of the survey questions, an unstructured exploratory interview was conducted with 3 junior and 3 senior physicians focusing on their requirements and perceptions toward mobile devices. The results were used to construct the questionnaire for the actual study.

The study was designed as an open web-based survey in 8 German university hospitals and conducted among physicians of all medical disciplines (Limesurvey). To prove the functionality of the survey and the clarity of the questions, a test run was sent to a small group of 25 anesthesiologists and critical care physicians in June 2019. Minor remarks and improvement recommendations were made and integrated in the final version of the online survey which was sent via email with a link to the survey that was valid for 19 weeks. Responsible contact persons in the respective hospitals forwarded the link to physicians in their hospitals. During the period of data collection, no bug fixes and content changes were made, and no unexpected events such as system failures or server downtime were observed. The local data protection officer and the local ethics committee were consulted and had no concerns regarding the study. The title page of the survey contained information regarding the length, the foreseen time for completion, and the purpose the questionnaire. Completion of the survey was taken as consent for scientific usage of the collected data.

The survey was divided into sections, one of which contained questions about mobile devices usage. Biographical questions were included in another section (see Multimedia Appendix 1 for the English version of the survey).

Different types of survey questions were prepared: closed-ended questions, open-ended questions, rating questions, Likert scale questions (4-point scale), multiple choice questions, and demographic questions. Most questions allowed the participants to give multiple answers. Answering questions was not compulsory, as we expected that mandatory answers increases the risk that participants do not complete the web-based survey. Only fully completed questionnaires were included in the analysis. It was taken into account that some items were not answered by all participants (indicated as no response) resulting in a variation in the total number of answers. The survey instructions stated that cordless telephones (such as digital enhanced cordless telecommunications known as DECT) without additional functions and digital message receivers are not included in the survey to keep a narrower definition of a mobile device.

\section{Statistical Analysis}

As this study aimed to provide a general overview over physicians' attitudes and expectations toward mobile devices, data were predominantly analyzed with descriptive counts and proportions, applying significance tests only in a few selected cases. For nominal variables with a particularly large number of values (eg, medical discipline), values were summarized into broad categories, if possible. Data are given as absolute numbers 
or their percentages; summaries are given as median and as interquartile range for ordinal data and mean and standard deviation for continuous variables. Some of the survey items allowed for multiple responses (eg, choose all that apply), thus invalidating the use of classical chi-square testing to check for associations between those items. For significance testing of multiple response item associations, the nonparametric bootstrap variant of the simultaneous pairwise marginal independence test proposed by Bilder and Loughin [35] was used, which was implemented in the MRCV package (version 0.3-3) [36] in R (version 4.0.1). To test for associations of score variables with single-response items, the Kruskal-Wallis rank sum test was used.
The 33 medical disciplines of the participants were classified into 6 categories (see Multimedia Appendix 2, Table S1) to identify dependencies between the discipline categories and the survey answers. Furthermore, the mobile devices question group, which investigates the current usage, the needs, and requirements of physicians, was simplified. For the analysis, the tasks conducted with mobile devices in 5 fields of application in stationary hospital care (defined as all fields of inpatient care) were categorized as follows: (1) oral and written communication; (2) documentation, organization, and information desk; (3) decision support, notifications, and alarms; (4) Education and professional training; and (5) self-monitoring by physicians (see Table 1).

Table 1. Fields of application of mobile devices in stationary hospital care.

\begin{tabular}{|c|c|}
\hline Categories & Functions \\
\hline 1. Oral/written communication & $\begin{array}{ll}\text { - } & \text { Official phone calls } \\
\text { - } & \text { Official text messages (eg, SMS, messenger) } \\
\text { - } & \text { Web conferences (eg, tumor conferences) }\end{array}$ \\
\hline 2. Documentation, organization, and information desk & $\begin{array}{l}\text { - } \quad \text { Time scheduling and workflow support } \\
\text { - } \quad \text { Mobile EHR } \mathrm{E}^{\mathrm{a}} \text { to look up patient information and for medical documentation } \\
\text { - } \quad \text { Written inter/intraprofessional communication (doctors, nurses, therapists, consult re- } \\
\text { - } \quad \text { To look up dosages, diagnoses and guidelines (online/offline) }\end{array}$ \\
\hline 3. Decision support, notifications, and alarms & $\begin{array}{l}\text { - Alarming while monitoring of vital signs } \\
\text { - (Early) warning system to prevent adverse effects (eg, pharmacological interaction) } \\
\text { - Decision support and definition of therapies }\end{array}$ \\
\hline 4. Education and professional training & - $\quad$ Education system for job training, education and professional training \\
\hline 5. Self-monitoring by physicians & - Monitoring of own vital signs/motion analysis (eg, pedometer, energy consumption) \\
\hline
\end{tabular}

${ }^{\mathrm{a}}$ EHR: electronic health record.

We developed a scoring system to analyze the participants' attitude toward mobile devices by assigning positive values to answers indicating a positive attitude toward mobile devices (fully disagree $=0$; fully agree $=3$ ) and negative values to EHR answers indicating a negative attitude (fully disagree $=0$; fully agree $=-3$ ). These values were summed for each participant and stratified by age groups, by medical disciplines, and by technical affinity.

\section{Results}

\section{Demographic and Professional Characteristics}

In total, 303 physicians with a mean clinical work experience of 12.7 years completed the survey. The full demographic and professional characteristics are given in Table 2. The participating physicians displayed a wide range of medical disciplines and the full range of discipline categories. The study population worked in all operational areas of the hospital, and physicians from all professional levels completed the web-based survey. 
Table 2. Demographic and professional characteristics.

\begin{tabular}{|c|c|}
\hline Characteristic & Value $(\mathrm{n}=303), \mathrm{n}(\%)$ \\
\hline \multicolumn{2}{|l|}{ Age range (years) } \\
\hline $18-24$ & $1(0.3)$ \\
\hline $25-34$ & $98(32.3)$ \\
\hline $35-44$ & $103(34.0)$ \\
\hline $45-54$ & $69(22.8)$ \\
\hline $55-65$ & $21(6.9)$ \\
\hline$>65$ & $3(1.0)$ \\
\hline No response & $8(2.6)$ \\
\hline \multicolumn{2}{|l|}{ Gender } \\
\hline Female & $121(39.9)$ \\
\hline Male & $173(57.1)$ \\
\hline No response & $9(3.0)$ \\
\hline \multicolumn{2}{|l|}{ Current occupation } \\
\hline Assistant physician & $101(33.3)$ \\
\hline Medical specialist & $49(16.2)$ \\
\hline Senior physician & $108(35.6)$ \\
\hline Clinic director & $28(9.2)$ \\
\hline Others & $6(2.0)$ \\
\hline No response & $11(3.6)$ \\
\hline \multicolumn{2}{|l|}{ Medical field/discipline } \\
\hline Anesthesiology/intensive care medicine & $75(24.8)$ \\
\hline Internal medicine & $53(17.5)$ \\
\hline Pediatrics & $25(8.3)$ \\
\hline Surgery & $22(7.3)$ \\
\hline Neurology & $14(4.6)$ \\
\hline Dermatology & $12(4.0)$ \\
\hline Microbiology, virology, infectiology & $10(3.3)$ \\
\hline Psychiatry and psychotherapy & $10(3.3)$ \\
\hline Psychosomatic medicine and psychotherapy & $8(2.6)$ \\
\hline Neurosurgery & $8(2.6)$ \\
\hline Ophthalmology & $7(2.3)$ \\
\hline Pathology & $7(2.3)$ \\
\hline Otorhinolaryngology & $5(1.7)$ \\
\hline Child and adolescent psychiatry and psychotherapy & $5(1.7)$ \\
\hline Laboratory medicine & $5(1.7)$ \\
\hline Radiology & $5(1.7)$ \\
\hline Urology & $5(1.7)$ \\
\hline Other disciplines/specialization & $43(14.2)$ \\
\hline \multicolumn{2}{|l|}{ Predominant workplace } \\
\hline Hospital ward & $123(40.6)$ \\
\hline Operating theatre & $106(35.0)$ \\
\hline Outpatient clinic & $100(33.0)$ \\
\hline
\end{tabular}




\begin{tabular}{ll}
\hline Characteristic & Value $(\mathrm{n}=303), \mathrm{n}(\%)$ \\
\hline Intensive care unit & $89(29.4)$ \\
Office & $50(16.5)$ \\
Laboratory & $33(10.9)$ \\
Functional area & $30(9.9)$ \\
Others & $15(5.0)$ \\
Clinical professional experience (years), mean (SD) & $12.7(9.3)$ \\
\hline
\end{tabular}

\section{Mobile Device Usage: Devices and Operation Purposes}

Almost all respondents had smartphones $(294 / 303,97.0 \%)$ and laptops or desktops $(280 / 303,92.4 \%)$ for private use outside the working environment, $61.7 \%$ (187/303) of the respondents used tablets, and 20.8\% (63/303) used wearables such as smartwatches and fitness trackers privately.
In clinical daily routine, $71.0 \%$ of physicians (215/303) used mobile devices. The operational purposes of mobile devices in clinical practice are widespread (Table 3). Predominantly, mobile devices are used for basic functions such as looking up information, oral and written communication (text messages, emails), and time scheduling.

Table 3. For which operation purposes do you use mobile devices in your clinical routine?

\begin{tabular}{ll}
\hline Operation purposes & Value $(\mathrm{n}=303), \mathrm{n}(\%)$ \\
\hline Phone calls & $154(50.8)$ \\
Text messages (eg, SMS, messenger) & $130(42.9)$ \\
Email communication & $157(51.8)$ \\
Look up of information & $190(62.7)$ \\
Mobile access to hospital information systems & $57(18.8)$ \\
Time scheduling & $141(46.5)$ \\
Private communication & $107(35.3)$ \\
Dictation of texts & $18(5.9)$ \\
Scientific work & $79(26.1)$ \\
Other & $14(4.6)$ \\
\hline
\end{tabular}

Almost $79 \%$ of all respondents $(238 / 303,78.6 \%)$ stated that they used private devices for official uses in daily clinical routine. The majority of the respondents stated that they used their private mobile device because they are not provided with an official mobile device in hospital care $(146 / 303,48.2 \%)$. Other reasons were the ability to work at home $(137 / 303,45.2 \%)$ and the fact that mobile work is only possible with their private mobile devices $(105 / 303,34.7 \%)$. Some respondents also stated that their private devices are better than the official device $(85 / 303,28.1 \%)$ and that private communication is only possible with their private mobile device $(65 / 303,21.5 \%)$.

\section{Perceived Ideal Device Versus Actual Time of Usage}

The vast majority of participating physicians rated tablets $(211 / 303,69.6 \%)$ and smartphones $(177 / 303,58.4 \%)$ as the most appropriate device for their area of application (Figure 1). A smaller group of respondents $(93 / 303,30.7 \%)$ ranked desktop computers as most appropriate, and a group of respondents (89/303, 29.4\%) regarded laptops as the most suitable device for their work area. Still 23 respondents (23/303, 7.6\%) rated paper as most suitable for their professional work. Respondents could choose more than one answer for this question, and the simultaneous pairwise marginal independence test revealed no significant differences in answers between the different age groups $\left(\chi_{\mathrm{s}}^{2}=34.19, P=.052\right)$. 
Figure 1. Percentage of respondents rating device as ideal device versus mean percentage of daily worktime used.

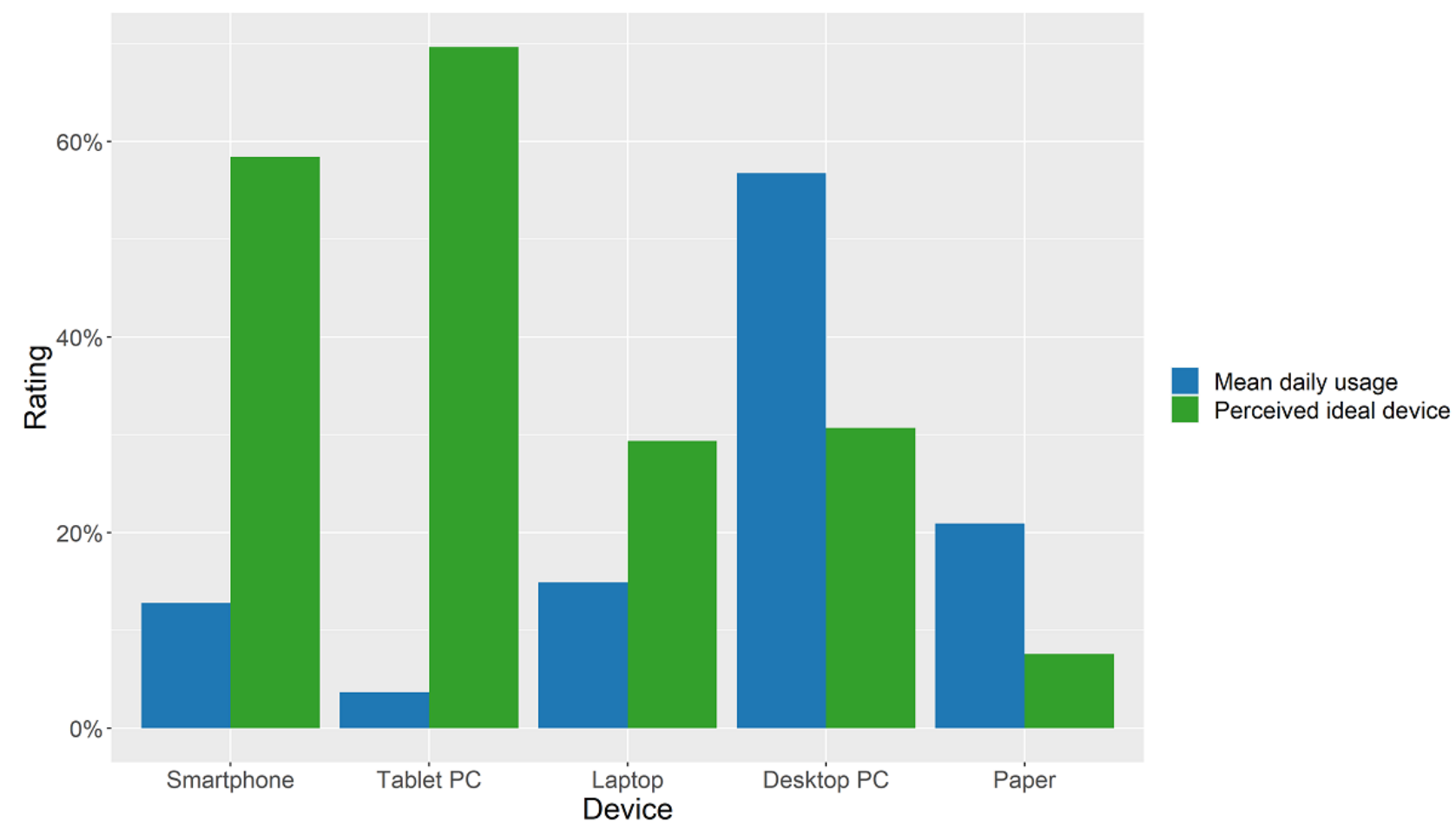

Contrasting their conception of ideal device usage, the physicians were asked to rate their actual time of usage of the devices during their daily total worktime. While most physicians rated smartphones and tablets as the perceived ideal device, in today's clinical practice, desktop computers and paper are predominantly used (Figure 1).

\section{Personal Opinion About Mobile Devices}

In another survey section, we asked about the personal opinion of physicians toward mobile devices in stationary hospital care. We inquired whether mobile devices are supportive tools, whether they should be implemented in stationary hospital care and whether they increase patient safety. Furthermore, we asked for data security and information safety concerns regarding

mobile devices and whether respondents fear an increasing workload or increasing operational supervision. For analysis, the statements "rather applies" and "fully applies" were taken as agreement. Most respondents (276/303, 91.1\%) agreed with the statement "A mobile device would support me in my work." Moreover, most physicians wish for the area-wide implementation of mobile devices in stationary patient care $(259 / 303,85.5 \%)$.

Regarding data security and information safety, a slight majority of $56.4 \%(171 / 303)$ of respondents expressed concerns. However, the large majority of 79.2\% (240/303) of respondents agreed that the usage of mobile devices could increase patient safety (Figure 2). 
Figure 2. Personal opinion about mobile devices.

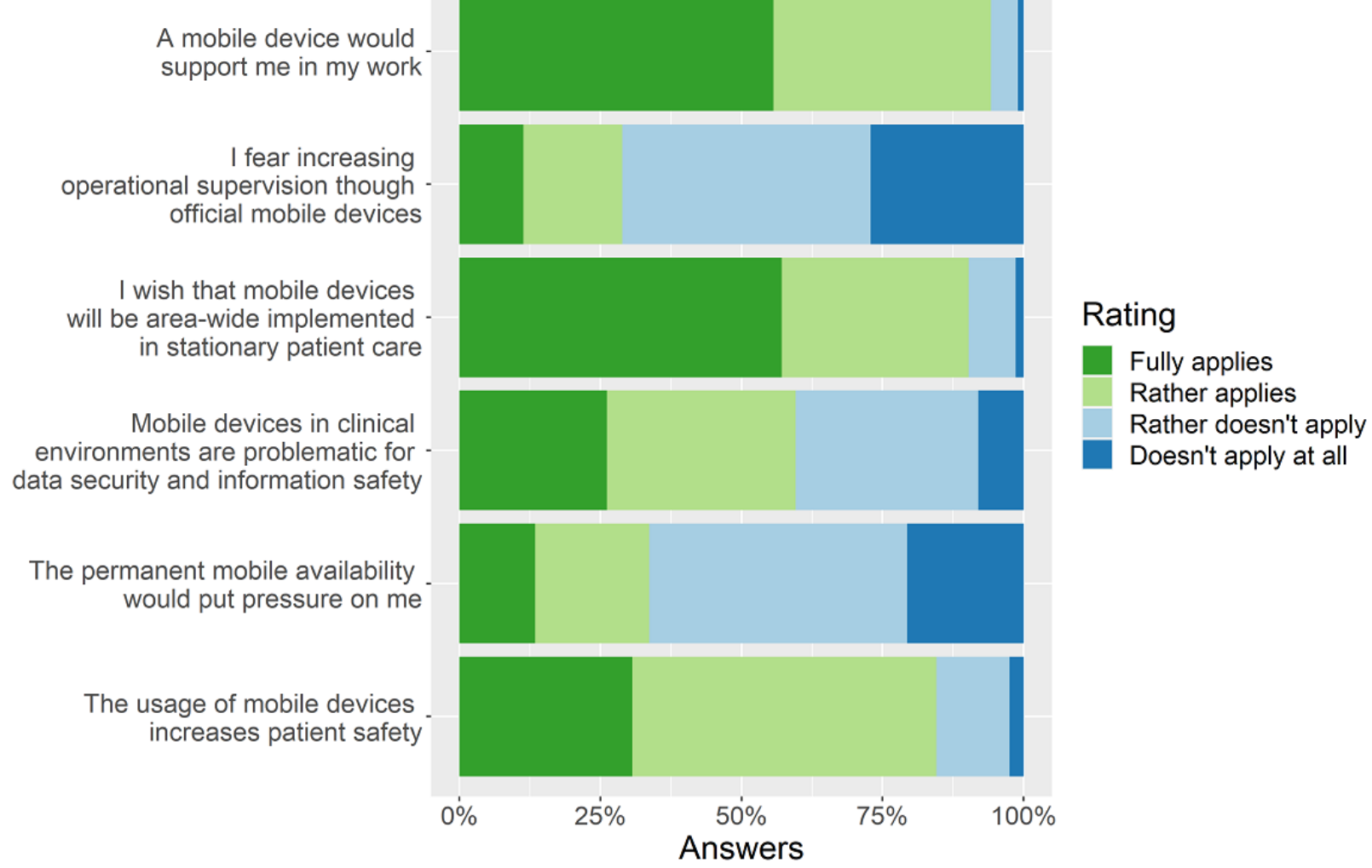

In sum, most physicians rated mobile devices as useful and In general, a Kruskal-Wallis test did not show significant supportive tools that should be implemented in stationary differences in the attitude toward mobile devices between age hospital care. groups $\left(H_{5}=7.29, P=.20\right.$; Figure 3$)$.

Figure 3. Attitude toward mobile devices stratified by age groups.

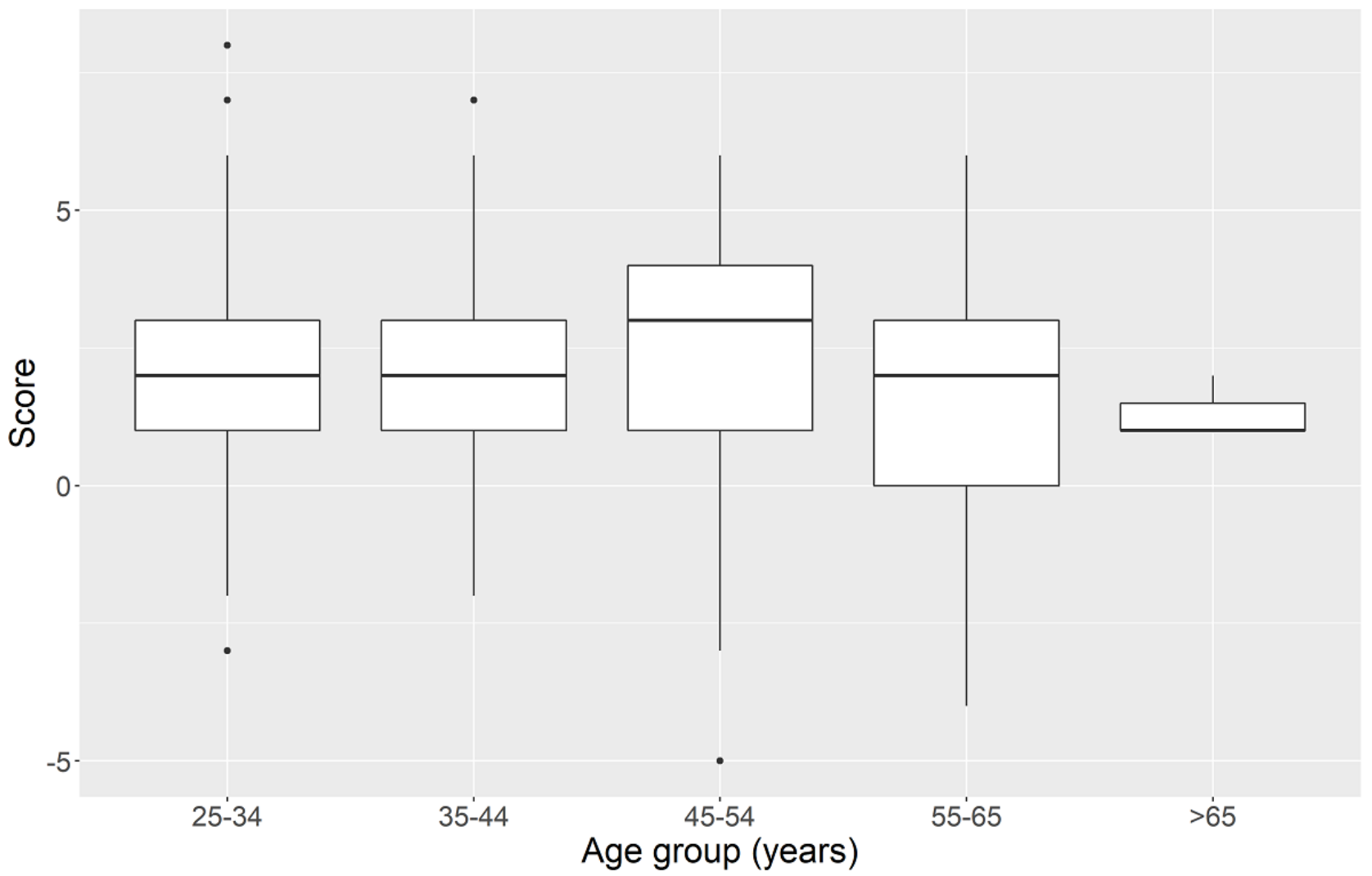




\section{Self-Reported Technical Affinity}

Overall, the study population reported a high technical affinity level (mean 4 out of 5).

There was a significant association between technical affinity and the preference of device in medical care $\left(\chi_{\mathrm{s}}^{2}=53.84, P<.001\right)$ showing that with increasing self-reported technical affinity the preference for smartphones and tablets increases compared to desktop computers (Figure 4).

The most optimistic respondents toward mobile devices were those who also had the highest self-reported technical affinity (Figure 5). With increasing technical affinity, the score for the attitude toward mobile devices increased $\left(H_{4}=17.31, P=.002\right)$.

Figure 4. Device preference stratified by (self-reported) technical affinity level.

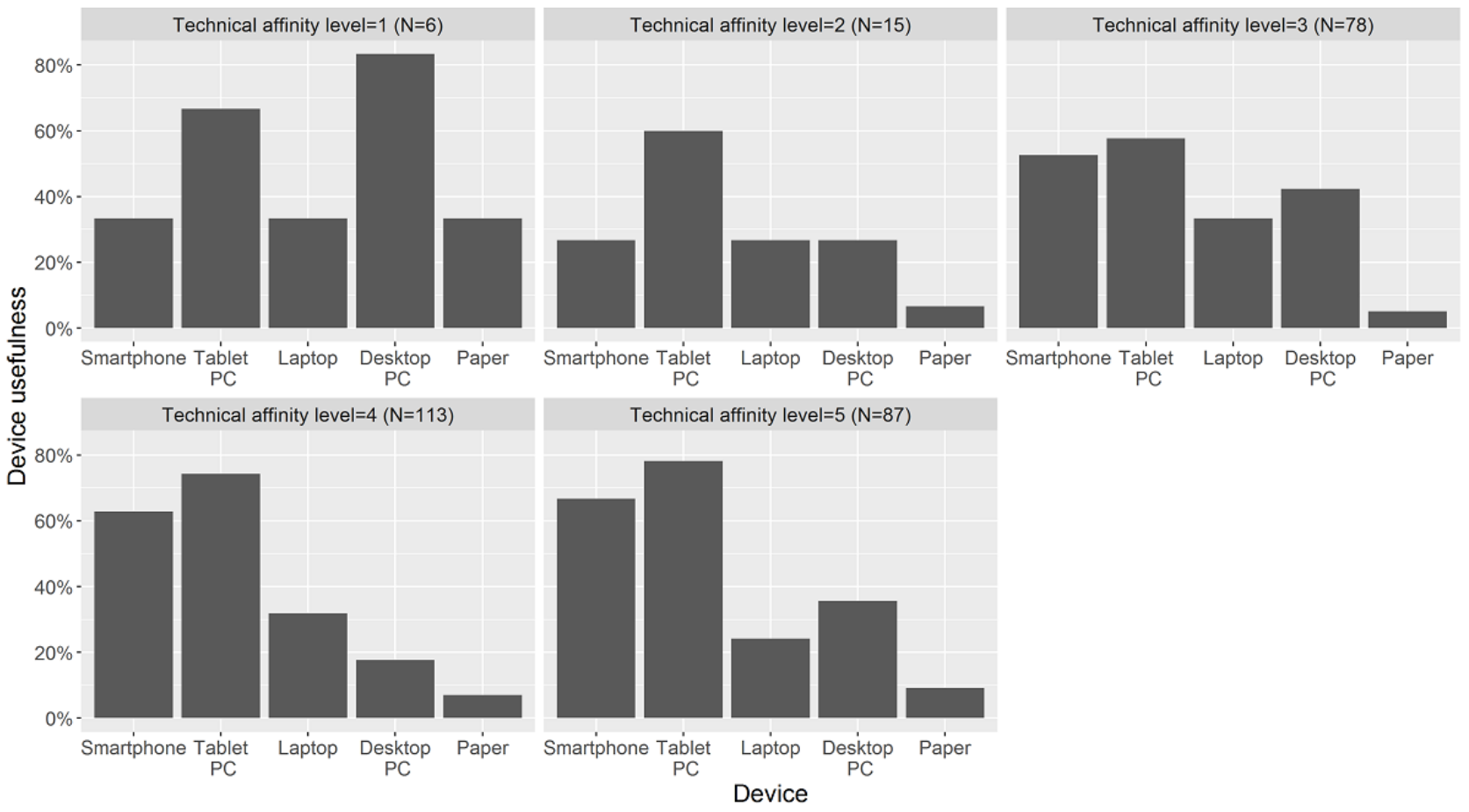

Figure 5. Attitude toward mobile devices stratified by (self-reported) technical affinity level.

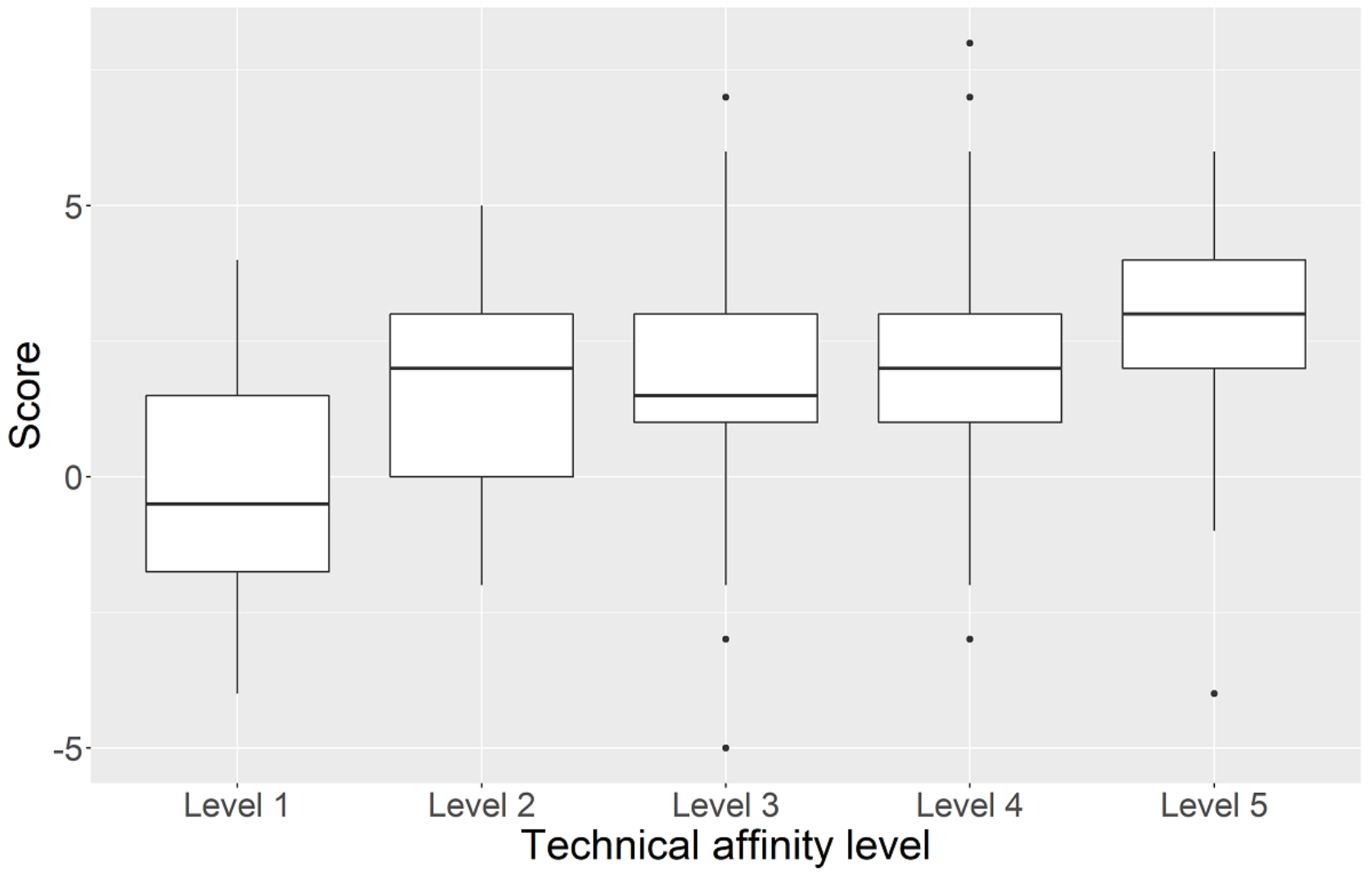




\section{Fields of Application and Desired Uses of Mobile Devices in Medicine}

Finally, we examined the actual use of mobile devices and which functions the participants desired to use in stationary hospital care, if available. Five major fields of application of mobile devices could be identified (Table 1). Within these fields, the following 4 functions were the most commonly used mobile device apps by physicians: official phone calls (171/303, $56.4 \%)$; official text messages (118/303, 38.9\%); looking up dosages, diagnoses, and guidelines (194/303, 64.0\%); and time scheduling and workflow support $(135 / 303,44.6 \%)$. The most desired mobile device uses were for (early) warning systems to prevent adverse effects in hospital care (eg, pharmacological interactions; 224/303, 73.9\%), for mobile EHR to look up patient information and for medical documentation $(211 / 303,69.6 \%)$, and for written instructions and recording procedures and examinations $(206 / 303,68.0 \%)$. The results can be found in Figure 6.

Figure 6. Fields of application and desired functions. EHR: electronic health record.

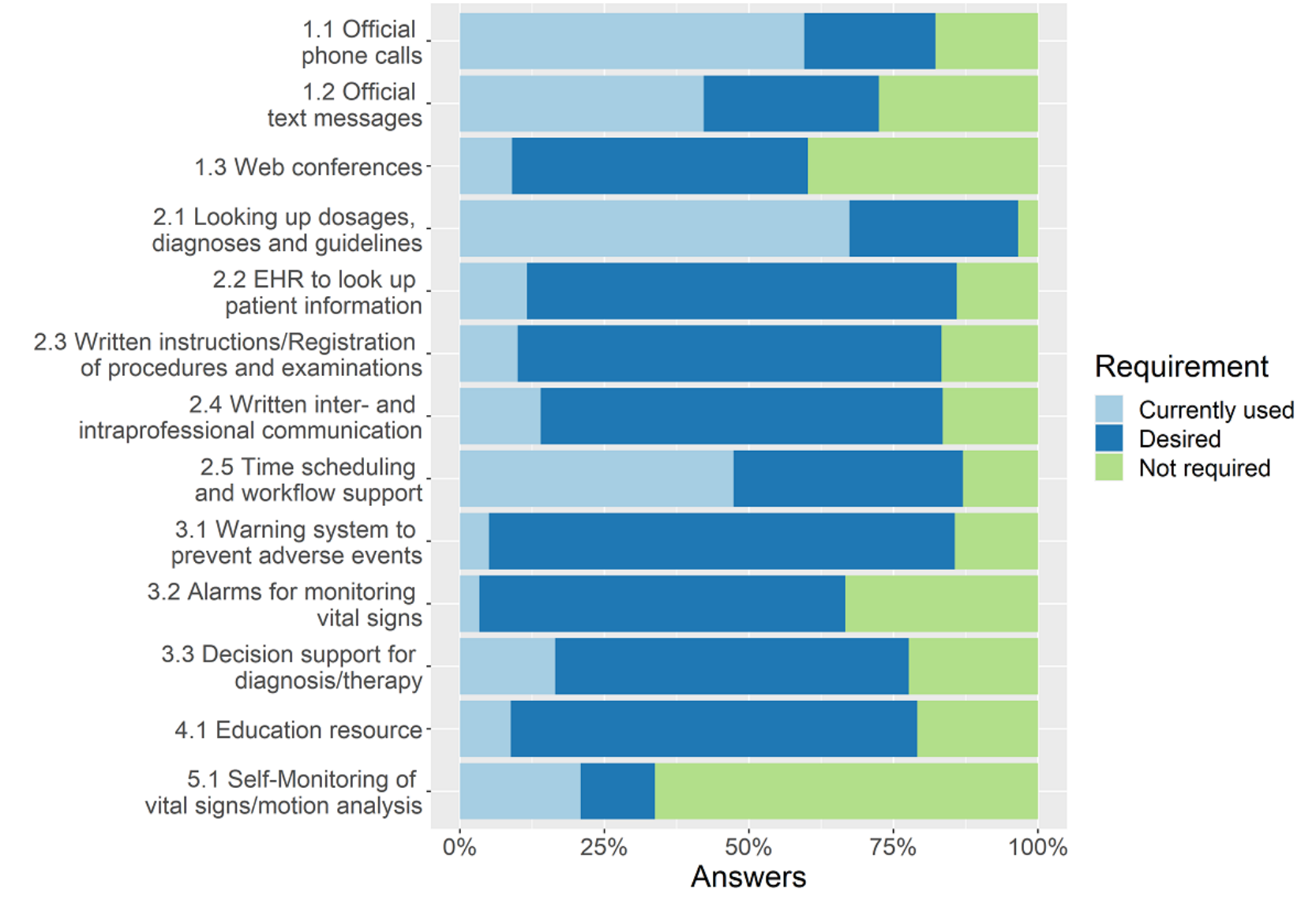

\section{Discussion}

\section{Current Situation and Physicians' Requirements}

In today's clinical practice, physicians are confronted with increasing amounts of patient information, information overload and information inaccessibility, endangering patient safety and potentially leading to fatal errors [37]. A substantial proportion of physicians use their private mobile devices for professional purposes, especially because they are not provided with official mobile devices for their work. Our survey results show that physicians expect that an official mobile device would support them in their work and increase patient safety. Most participants used mobile devices in hospitals for communication and organization (phone calls, text messages, time scheduling, and information), and thus, to increase the efficiency in their workplaces [30]. Among our study population, most physicians would prefer to use official devices but accept using their private mobile devices for professional purposes in stationary hospital care if there is no alternative.

\section{Potential Benefits for Physicians and Patient Care}

Currently, physicians in hospital care spend a large amount of their worktime performing documentation in clinical information systems [38,39]. Therefore, physicians want to use mobile devices for documentation and recording procedures in these systems. Today, the tasks of documentation and recording procedures are most commonly performed with a desktop computer and cannot be performed in equal quality on a smaller mobile device. Thus, not every task in clinical care can be transferred from a desktop computer to a smartphone or a tablet without changing the process. Drews et al [16] examined the impact of the form factor of various mobile devices and desktop computers on the usability of EHRs; the authors concluded that even the largest form of a mobile device does not perform as well as a desktop computer for the usage of EHR. Consequently, the processes of documentation and recording procedures need to be changed before they can be performed in equal quality on a tablet or a smartphone in hospital care. 
Smartphones and tablets at the point of care could support in-hospital physicians (eg, with functionalities such as taking notes via voice recognition for clinical documentation instead of keyboard-and-mouse interface) [40,41]. Payne et al [42] described the implementation of a smartphone-based system as a supporting system with automated speech recognition integrated in a commercial EHR; the mobile supporting system that was described has the potential to reduce the documentation burden of doctors and nurses, which is perceived as one of the big problems in today's health care [38,39]. We assume that physicians would benefit from mobile devices with automated speech recognition for documentation in and access to clinical information systems. Nevertheless, 48.2\% (146/303) of all respondents are not provided with official mobile devices for these uses in hospital care and, as shown in Figure 6, less than $11 \%$ are already using a mobile EHR in our study population. As a precondition of continual documentation of patient information, mobile apps need to be integrated in central information systems in hospitals by using technical and semantic interoperability standards.

German hospitals are no exception in the rare use of mobile devices even for basic tasks, such as documentation in clinical information systems. However, physicians are open to an increasing use of more advanced mobile uses such as decision support systems on mobile devices in their clinical practice. Large proportions of physicians stated the wish to be able to use (early) warning systems for prevention of adverse effects, possibly harmful pharmacological interactions, smart monitoring of vital signs and decision support, and definition of therapies in clinical practice.

\section{Regulatory Challenges}

The development of medical software such as mobile apps, especially those subject to new European Medical Device Regulation $2017 / 745$, is a complex process including many obligations and requirements for manufacturers [43]. In addition to the regulatory legal requirements of the European Medical Device Regulation, health care professionals ask for the certification of health care apps [44].

The majority of physicians are aware that mobile devices may have implications on data security and information safety, while at the same time increasing patient safety. To ensure data security and information safety in hospitals, we suggest that apps that support health care professionals in performing complex and critical tasks should be installed and operated on official smartphones and tablets. For fulfilling information security standards, the devices should be provided and administrated through the hospital information technology departments. This could also help to reduce the potential legal grey area of using private mobile devices in the clinical environments for official purposes. Therefore, hospitals should implement a mobile device management process to safeguard the secure operation of mobile devices. Due to the increasing complexity of mobile device uses and increasing competencies of physicians in using mHealth apps, there is a need for a process to implement, teach, supervise, and evaluate clinical mHealth as well as mobile device and app competencies [24,45]. Finally, the added value of apps on mobile devices for physicians should be scientifically proven before being implemented in hospital care.

\section{Strengths and Limitations}

This web-based survey covered the use of mobile devices for physicians in stationary hospital care in 8 university hospitals in different regions in Germany. As far as we know, it is the first survey covering this study population and evaluating the usage of, requirements for, and expectations toward mobile devices. University hospitals accommodate all medical disciplines and physicians involved in patient care, research, teaching, and training. Thus, a wide range of medical disciplines was covered by the respondents.

Usage of and requirements for mobile devices such as mobile (telemonitoring) apps for patients (self-monitoring and mobile self-reporting [46]) or diagnostic instruments connected to a mobile device (eg, iECG or handheld ultrasound [3]) are not the subject matter of this study. We also did not distinguish between official mobile devices as personalized or shared mobile devices.

A limitation of the recruitment method of the web-based survey is potential volunteer bias. The mean self-reported technical affinity of the study population was 4 out of 5 , suggesting that most participating physicians had a relatively high affinity for technology, in general and in medical practice. Consequently, further research, using paper-based and personal-oral survey methods, is needed to reach physicians with a lower technical affinity.

\section{Conclusions}

So far, the widespread use of official mobile devices such as smartphones and tablets has not become reality in stationary hospital care in German (university) hospitals. As long as physicians are predominantly using their private devices in clinical care, the usage of advanced apps with a deeper integration into the clinical information system infrastructure to support physicians remains uncertain.

Nevertheless, among the participating physicians of German university hospitals, technical affinity is high, and they have a very positive attitude toward mobile devices for clinical care. With our results, we demonstrated that the majority of the participating physicians used mobile devices for basic functionalities in hospital care. Although most physicians would prefer to work with mobile devices for documentation, writing instructions, and recording procedures in clinical information systems, a desktop computer is generally used for these tasks. Furthermore, physicians are willing to use their mobile devices for more progressive uses such as decision support systems or early warning systems. Thus, reasons for the low usage of official mobile devices in German hospitals are not the potential users, but rather regulatory, financial and organizational challenges, and missing interoperability standards.

While most physicians think that mobile devices would support their work and increase patient safety, they also mentioned concerns regarding data security and information safety. 


\section{Acknowledgments}

This publication of the Smart Medical Information Technology for Healthcare consortium was supported by the German Federal Ministry of Education and Research (grant numbers 01ZZ1803B and 01ZZ1803C).

\section{Authors' Contributions}

$\mathrm{OM}$ and SF designed the survey and set up the web-based survey. OM, JG, and SF analyzed the data. OM wrote the manuscript. $\mathrm{SF}, \mathrm{JB}, \mathrm{JK}, \mathrm{JG}, \mathrm{SD}$, and GM revised the article. All authors approved the final draft.

\section{Conflicts of Interest}

None declared.

\section{Multimedia Appendix 1}

Survey on the usage of mobile devices in stationary hospital care.

[DOC File, 113 KB-Multimedia Appendix 1]

\section{Multimedia Appendix 2}

Categories of medical disciplines.

[DOC File, 48 KB-Multimedia Appendix 2]

\section{References}

1. Tenzer F. Anzahl der Nutzer von Smartphones in Deutschland bis 2019. Statista. 2019. URL: https://de.statista.com/statistik/ daten/studie/198959/umfrage/anzahl-der-smartphonenutzer-in-deutschland-seit-2010/ [accessed 2020-07-20]

2. Steinhubl SR, Muse ED, Topol EJ. The emerging field of mobile health. Sci Transl Med 2015 Apr 15;7(283):283rv3 [FREE Full text] [doi: 10.1126/scitranslmed.aaa3487] [Medline: 25877894]

3. Bhavnani SP, Narula J, Sengupta PP. Mobile technology and the digitization of healthcare. Eur Heart J 2016 May 07;37(18):1428-1438 [FREE Full text] [doi: 10.1093/eurheartj/ehv770] [Medline: 26873093]

4. Triantafyllidis A, Kondylakis H, Votis K, Tzovaras D, Maglaveras N, Rahimi K. Features, outcomes, and challenges in mobile health interventions for patients living with chronic diseases: A review of systematic reviews. Int J Med Inform 2019 Dec;132:103984. [doi: 10.1016/j.ijmedinf.2019.103984] [Medline: 31605884]

5. Sarfo FS, Ovbiagele B. Mobile health for stroke: a promising concept for research and practice. Mhealth 2017;3:4 [FREE Full text] [doi: 10.21037/mhealth.2017.02.01] [Medline: 28300225]

6. Dimond R, Bullock A, Lovatt J, Stacey M. Mobile learning devices in the workplace: 'as much a part of the junior doctors' kit as a stethoscope'? BMC Med Educ 2016 Aug 17;16(1):207 [FREE Full text] [doi: 10.1186/s12909-016-0732-z] [Medline: 27530343]

7. Vandelanotte C, Van Itallie A, Brown W, Mummery WK, Duncan MJ. Every step counts: understanding the success of implementing the 10,000 steps project. Stud Health Technol Inform 2020 Mar 02;268:15-30. [doi: 10.3233/SHTI200003] [Medline: 32141876]

8. Ahuja N, Ozdalga E, Aaronson A. Integrating mobile fitness trackers into the practice of medicine. Am J Lifestyle Med 2017;11(1):77-79 [FREE Full text] [doi: 10.1177/1559827615583643] [Medline: 30202316]

9. Saxon LA. Mobile health application solutions. Circ Arrhythm Electrophysiol 2016 Feb;9(2):e002477. [doi: 10.1161/CIRCEP.115.002477] [Medline: 26810595]

10. Goh G, Tan NC, Malhotra R, Padmanabhan U, Barbier S, Allen JC, et al. Short-term trajectories of use of a caloric-monitoring mobile phone app among patients with type 2 diabetes mellitus in a primary care setting. J Med Internet Res 2015 Feb 03;17(2):e33 [FREE Full text] [doi: 10.2196/jmir.3938] [Medline: 25648130]

11. Liu X, Sutton PR, McKenna R, Sinanan MN, Fellner BJ, Leu MG, et al. Evaluation of secure messaging applications for a health care system: a case study. Appl Clin Inform 2019 Jan;10(1):140-150 [FREE Full text] [doi: 10.1055/s-0039-1678607] [Medline: $\underline{\text { 30812040] }}$

12. Rokadiya S, McCaul JA, Mitchell DA, Brennan PA. Leading article: Use of smartphones to pass on information about patients - what are the current issues? Br J Oral Maxillofac Surg 2016 Jul;54(6):596-599. [doi: 10.1016/j.bjoms.2016.04.020] [Medline: 27185230]

13. Househ M. The role of short messaging service in supporting the delivery of healthcare: an umbrella systematic review. Health Informatics J 2016 Jun;22(2):140-150 [FREE Full text] [doi: 10.1177/1460458214540908] [Medline: 25038203]

14. Mars M, Scott RE. WhatsApp in clinical practice: a literature review. Stud Health Technol Inform 2016;231:82-90. [Medline: 27782019] 
15. Wu R, Appel L, Morra D, Lo V, Kitto S, Quan S. Short message service or disService: issues with text messaging in a complex medical environment. Int J Med Inform 2014 Apr;83(4):278-284. [doi: 10.1016/j.ijmedinf.2014.01.003] [Medline: 24495802]

16. Drews FA, Zadra JR, Gleed J. Electronic health record on the go: device form factor and Fitts' law. Int J Med Inform 2018 Mar;111:37-44. [doi: 10.1016/j.ijmedinf.2017.12.010] [Medline: 29425632]

17. Saleem JJ, Savoy A, Etherton G, Herout J. Investigating the need for clinicians to use tablet computers with a newly envisioned electronic health record. Int J Med Inform 2018 Feb;110:25-30. [doi: 10.1016/j.ijmedinf.2017.11.013] [Medline: 29331252]

18. Schooley B, Walczak S, Hikmet N, Patel N. Impacts of mobile tablet computing on provider productivity, communications, and the process of care. Int J Med Inform 2016 Apr;88:62-70. [doi: 10.1016/j.ijmedinf.2016.01.010] [Medline: 26878764]

19. Motulsky A, Wong J, Cordeau J, Pomalaza J, Barkun J, Tamblyn R. Using mobile devices for inpatient rounding and handoffs: an innovative application developed and rapidly adopted by clinicians in a pediatric hospital. J Am Med Inform Assoc 2017 Apr 01;24(e1):e69-e78 [FREE Full text] [doi: 10.1093/jamia/ocw107] [Medline: 27554824]

20. Richardson KM, Fouquet SD, Kerns E, McCulloh RJ. Impact of mobile device-based clinical decision support tool on guideline adherence and mental workload. Acad Pediatr 2019;19(7):828-834 [FREE Full text] [doi: 10.1016/j.acap.2019.03.001] [Medline: 30853573]

21. Machado JP, Lam XT, Chen J. Use of a clinical decision support tool for the management of traumatic dental injuries in the primary dentition by novice and expert clinicians. Dent Traumatol 2018 Apr;34(2):120-128. [doi: 10.1111/edt.12390] [Medline: 29476702]

22. Huang CY, Cheng PL, Chang PL. Using a mobile device application to support emergency clinicians in diagnosing pulmonary embolism. Stud Health Technol Inform 2017;245:1363. [Medline: 29295442]

23. Dexheimer JW, Borycki EM. Use of mobile devices in the emergency department: a scoping review. Health Informatics J 2015 Dec;21(4):306-315 [FREE Full text] [doi: 10.1177/1460458214530137] [Medline: 24782479]

24. Hilty DM, Chan S, Torous J, Luo J, Boland RJ. Mobile health, smartphone/device, and apps for psychiatry and medicine: competencies, training, and faculty development issues. Psychiatr Clin North Am 2019 Sep;42(3):513-534. [doi: 10.1016/j.psc. 2019.05.007] [Medline: 31358129]

25. Mackay BJ, Anderson J, Harding T. Mobile technology in clinical teaching. Nurse Educ Pract 2017 Jan;22:1-6. [doi: 10.1016/j.nepr.2016.11.001] [Medline: 27871040]

26. Han H, Nelson E, Wetter N. Medical students' online learning technology needs. Clin Teach 2014 Feb;11(1):15-19. [doi: 10.1111/tct.12092] [Medline: 24405913]

27. Bedi HS, Yucel EK. "I just bought my residents iPads... now what?" the integration of mobile devices into radiology resident education. AJR Am J Roentgenol 2013 Oct;201(4):704-709. [doi: 10.2214/AJR.13.10674] [Medline: 24059358]

28. Tanaka PP, Hawrylyshyn KA, Macario A. Use of tablet (iPad®) as a tool for teaching anesthesiology in an orthopedic rotation. Rev Bras Anestesiol 2012;62(2):214-222 [FREE Full text] [doi: 10.1016/S0034-7094(12)70119-8] [Medline: $\underline{22440376]}$

29. DiFrancisco-Donoghue J, Jung M, Stangle A, Werner WG, Zwibel H, Happel P, et al. Utilizing wearable technology to increase physical activity in future physicians: a randomized trial. Prev Med Rep 2018 Dec;12:122-127 [FREE Full text] [doi: 10.1016/j.pmedr.2018.09.004] [Medline: 30234000]

30. Nerminathan A, Harrison A, Phelps M, Alexander S, Scott KM. Doctors' use of mobile devices in the clinical setting: a mixed methods study. Intern Med J 2017 Mar;47(3):291-298. [doi: 10.1111/imj.13349] [Medline: 27925381]

31. Ulger F, Esen S, Dilek A, Yanik K, Gunaydin M, Leblebicioglu H. Are we aware how contaminated our mobile phones with nosocomial pathogens? Ann Clin Microbiol Antimicrob 2009 Mar 06;8:7 [FREE Full text] [doi: 10.1186/1476-0711-8-7] [Medline: 19267892]

32. Attri JP, Khetarpal R, Chatrath V, Kaur J. Concerns about usage of smartphones in operating room and critical care scenario. Saudi J Anaesth 2016;10(1):87-94 [FREE Full text] [doi: 10.4103/1658-354X.169483] [Medline: 26952181]

33. van Velthoven MH, Wyatt JC, Meinert E, Brindley D, Wells G. How standards and user involvement can improve app quality: a lifecycle approach. Int J Med Inform 2018 Oct;118:54-57. [doi: 10.1016/j.ijmedinf.2018.08.003] [Medline: $\underline{30153922]}$

34. Krebs P, Duncan DT. Health app use among US mobile phone owners: a national survey. JMIR Mhealth Uhealth 2015 Nov 04;3(4):e101 [FREE Full text] [doi: 10.2196/mhealth.4924] [Medline: 26537656]

35. Bilder CR, Loughin TM. Testing for marginal independence between two categorical variables with multiple responses. Biometrics 2004 Mar;60(1):241-248. [doi: 10.1111/j.0006-341X.2004.00147.x] [Medline: 15032795]

36. Koziol NA, Bilder CR. MRCV: Methods for Analyzing Multiple Response Categorical Variables (MRCVs). R Package Version 0.3-3. 2014. URL: https://CRAN.R-project.org/package=MRCV [accessed 2020-07-20]

37. Pickering BW, Gajic O, Ahmed A, Herasevich V, Keegan MT. Data utilization for medical decision making at the time of patient admission to ICU. Crit Care Med 2013 Jun;41(6):1502-1510. [doi: 10.1097/CCM.0b013e318287f0c0] [Medline: 23528804]

38. Tawfik DS, Profit J, Webber S, Shanafelt TD. Organizational factors affecting physician well-being. Curr Treat Options Pediatr 2019 Mar;5(1):11-25 [FREE Full text] [doi: 10.1007/s40746-019-00147-6] [Medline: 31632895] 
39. Collins S, Couture B, Kang MJ, Dykes P, Schnock K, Knaplund C, et al. Quantifying and visualizing nursing flowsheet documentation burden in acute and critical care. AMIA Annu Symp Proc 2018;2018:348-357 [FREE Full text] [Medline: $\underline{30815074]}$

40. Lorenzetti DL, Quan H, Lucyk K, Cunningham C, Hennessy D, Jiang J, et al. Strategies for improving physician documentation in the emergency department: a systematic review. BMC Emerg Med 2018 Oct 25;18(1):36 [REEE Full text] [doi: 10.1186/s12873-018-0188-z] [Medline: $\underline{30558573}$ ]

41. Collier R. Rethinking EHR interfaces to reduce click fatigue and physician burnout. CMAJ 2018 Aug 20;190(33):E994-E995 [FREE Full text] [doi: 10.1503/cmaj.109-5644] [Medline: 30127043]

42. Payne TH, Alonso WD, Markiel JA, Lybarger K, White AA. Using voice to create hospital progress notes: Description of a mobile application and supporting system integrated with a commercial electronic health record. J Biomed Inform 2018 Jan;77:91-96 [FREE Full text] [doi: 10.1016/j.jbi.2017.12.004] [Medline: 29233669]

43. Keutzer L, Simonsson US. Medical device apps: an introduction to regulatory affairs for developers. JMIR Mhealth Uhealth 2020 Jun 26;8(6):e17567 [FREE Full text] [doi: 10.2196/17567] [Medline: 32589154]

44. Mayer MA, Rodríguez Blanco O, Torrejon A. Use of health apps by nurses for professional purposes: web-based survey study. JMIR Mhealth Uhealth 2019 Nov 01;7(11):e15195 [FREE Full text] [doi: 10.2196/15195] [Medline: 31682587]

45. Hilty D, Chan S, Torous J, Luo J, Boland R. A framework for competencies for the use of mobile technologies in psychiatry and medicine: scoping review. JMIR Mhealth Uhealth 2020 Feb 21;8(2):e12229 [FREE Full text] [doi: 10.2196/12229]

[Medline: 32130153]

46. Triantafyllidis AK, Velardo C, Salvi D, Shah SA, Koutkias VG, Tarassenko L. A survey of mobile phone sensing, self-reporting, and social sharing for pervasive healthcare. IEEE J Biomed Health Inform 2017 Jan;21(1):218-227. [doi: 10.1109/JBHI.2015.2483902] [Medline: 26441432]

\title{
Abbreviations \\ EHR: electronic health record \\ mHealth: mobile health
}

\author{
Edited by $G$ Eysenbach, $R$ Kukafka; submitted 03.09.20; peer-reviewed by L van Velsen; comments to author 25.09.20; revised version \\ received 06.10.20; accepted 28.10.20; published 21.12 .20 \\ Please cite as: \\ Maassen O, Fritsch S, Gantner J, Deffge S, Kunze J, Marx G, Bickenbach J \\ Future Mobile Device Usage, Requirements, and Expectations of Physicians in German University Hospitals: Web-Based Survey \\ J Med Internet Res 2020;22(12):e23955 \\ URL: http://www.jmir.org/2020/12/e23955/ \\ doi: $\underline{10.2196 / 23955}$ \\ PMID: 33346735
}

(C) Oliver Maassen, Sebastian Fritsch, Julia Gantner, Saskia Deffge, Julian Kunze, Gernot Marx, Johannes Bickenbach. Originally published in the Journal of Medical Internet Research (http://www.jmir.org), 21.12.2020. This is an open-access article distributed under the terms of the Creative Commons Attribution License (https://creativecommons.org/licenses/by/4.0/), which permits unrestricted use, distribution, and reproduction in any medium, provided the original work, first published in the Journal of Medical Internet Research, is properly cited. The complete bibliographic information, a link to the original publication on http://www.jmir.org/, as well as this copyright and license information must be included. 